\title{
Contraceptive prevalence and determinants among women of reproductive age group in Ogbomoso, Oyo State, Nigeria
}

This article was published in the following Dove Press journal:

Open Access Journal of Contraception

29 March 2016

Number of times this article has been viewed

\author{
Adewale S Adeyemi' \\ Adenike I Olugbenga-Bello² \\ Oluwatosin A Adeoye ${ }^{3}$ \\ Moshood O Salawu ${ }^{3}$ \\ Adesola A Aderinoye ${ }^{3}$ \\ Michael A Agbaje' \\ 'Department of Obstetrics and \\ Gynaecology, ${ }^{2}$ Department of \\ Community Medicine, Faculty \\ of Clinical Sciences, College of \\ Health Sciences, Ladoke Akintola \\ University of Technology (LAUTECH), \\ Osogbo, Osun State, ${ }^{3}$ Department \\ of Community Medicine, LAUTECH \\ Teaching Hospital, Ogbomoso, Oyo \\ State, Nigeria
}

Background: The fertility rate in Nigeria is 5.7 children per woman. The contraceptive prevalence rate has been found to be low at $15 \%$ in 2013, compared to other countries such as the US and Pakistan.

Objective: The study aimed to assess the contraceptive prevalence among women of reproductive age in Ogbomoso town, and determinants of use, with a view to make appropriate recommendations that will enhance the uptake of family planning services.

Materials and methods: This is a descriptive cross-sectional study conducted with 560 respondents, using a multistage sampling technique. Data were retrieved using a semi-structured, pretested questionnaire.

Results: All the respondents were aware of contraception; however, only 49.7\% (271) had ever used any method, while $25.4 \%$ (69) of the number who had ever used contraception were currently using a method. The methods being used were the traditional type (four [5.9\%]), natural type (two [3.0\%]), and modern type (63 [91.1\%]). The predictors of contraception use included the age group of 40-49 years (odds ratio [OR] 14.1; confidence interval [CI] 3.06-73.24; $P=0.0001)$; the married women were approximately four times more likely to use contraception than the single women (OR 4.5; CI 3.03-6.72; $P<0.0001$ ). The women with tertiary level of education were three times more likely to use contraception than those without formal education (OR 3.1; CI 1.13-9.95; $P=0.0268$ ), and the odds ratio of respondents with a positive attitude to using contraception more than those with negative attitude was 2 (OR 2; CI $1.41-2.91 ; P<0.0001)$.

Conclusion: In light of the advantages associated with contraception use, there needs to be a conscious effort, especially among health care workers, to educate women about contraception and encourage its use.

Keywords: contraception, women of reproductive age, prevalence, determinants

\section{Introduction}

Developing countries are characterized by rapid population growth which is usually due to high fertility, high birth rates, and low contraceptive prevalence rate. ${ }^{1}$ In Sub-Saharan Africa, the rate of population growth is high compared to the rest of the world. ${ }^{2}$ Consequently, the number of people in need of health and education and basic infrastructure, among other public benefits, is enormous. This in turn requires large amounts of resources and personnel, and it may be an impediment toward the realization of the Millennium Development Goals. ${ }^{3}$

The International Conference on Population and Development in 1994 affirmed the importance of providing family planning within a rights-based framework and as part
Correspondence: Adenike I Olugbenga-Bello Department of Community Medicine, Faculty of Clinical Sciences, College of Health Sciences, Ladoke Akintola University of Technology (LAUTECH), PMB 4400, Osogbo, Osun State, Nigeria Email nike_bello@yahoo.com 
of a comprehensive set of services to meet individual reproductive health needs that would also address broader development concerns. ${ }^{4}$

Promotion of family planning in countries with high birth rates has the potential of reducing poverty and hunger, while at the same time averting $32 \%$ of all maternal deaths and nearly $10 \%$ of child mortality. ${ }^{4}$ Unintended pregnancy poses a major challenge to reproductive health. ${ }^{5}$ Each year, $~ 210$ million women around the world become pregnant, ${ }^{6}$ among which $36 \%$ are unplanned and/or unwanted. ${ }^{7}$ Nigeria currently has a high rate of maternal mortality, ${ }^{8}$ and $\sim 40 \%$ of these maternal deaths are due to complications of unsafe abortions as a response to unwanted pregnancy. ${ }^{9,10}$ The fertility rate in Nigeria is 5.7 children per woman. ${ }^{11}$ Contraceptive prevalence rate has been found to be low at $13 \%$ in $2008^{12}$ and with a minimal increase of $3 \%$ in $2013 .{ }^{13}$ This is very low compared to other countries such as the US and Pakistan. ${ }^{11}$

The overall goal of National Policy on Population for Sustainable Development launched in February 2005 by the Federal Government of Nigeria was based on the principle that achieving a higher quality of life for people today should not jeopardize the ability of future generations to meet their own needs. ${ }^{14,15}$ The main targets of the program were to reduce the national population growth rate to 2 percent or lower by 2015 , reduce the total fertility rate by at least 0.6 children every 5 years by encouraging child spacing through the use of family planning, and increase the contraceptive prevalence rate for modern methods by at least two percentage points per year through the use of family planning. ${ }^{15}$ If access to family planning services was increased, the unmet need for family planning could be addressed, thereby reducing the risk of maternal deaths, ${ }^{4}$ slowing the population growth rate, and reducing the costs of meeting Millennium Development Goals in terms of universal primary education, which is influenced by the number of children in need of education. ${ }^{16}$

Family planning services offer various benefits to the household, country, and the world at large. They permit individuals to influence the timing and the number of births, which is likely to save lives of children. By reduction of unwanted pregnancies, family planning services can reduce injury, illness, and death associated with child birth, abortions, and sexually transmitted infections (STIs) including HIV/AIDS. ${ }^{4,17}$ Furthermore, family planning contributes to reduction in population growth which subsequently leads to poverty reduction and preservation of the environment as well as demand for public goods and services. ${ }^{4}$ In spite of all the advantages and availability of family planning services, there is still persistently high fertility in Nigeria. ${ }^{11}$ Although there is widespread awareness with regard to contraception in Nigeria, ${ }^{13}$ there is no proportional increase in the adoption of the contraception measures, a pointer to the fact that there are other variables that determine the uptake of contraception in Nigeria. Previous studies have explored the determinants of contraceptive use among women of reproductive age; in most cases they have included both demographic and socioeconomic factors. ${ }^{1,15,18}$ Adebowale et al found age, religion, residence, education, ethnicity, and media exposure to family planning as significant predictors of current use of any contraceptive method. ${ }^{15}$ Positive attitude to reproductive health issues have also been said to increase contraception use, and it was concluded that changes in attitude toward contraception may increase practice of contraception in Nigeria. ${ }^{19}$

Ogbomoso is the second largest city in Oyo State by population, and it also has a higher institution of learning, thus the city has many women in their reproductive age group whose contraceptive practice is unknown; research on contraceptive use in Ogbomoso is thus indispensable. This study therefore assessed the contraceptive prevalence as well as examined the predictors of contraceptive use among women of reproductive age group in Ogbomoso town, Oyo State, South-West Nigeria, with a view to make appropriate recommendations that will enhance the uptake of family planning services.

\section{Methodology \\ Study area}

The area selected for this study was Ogbomoso in Oyo State, located in the south-western part of Nigeria. It is $\sim 95 \mathrm{~km}$ northwest of the Oyo State capital (Ibadan). Ogbomoso has five local government areas (LGAs) with each having ten wards. The LGAs are located in the regions of Ogbomoso North, Ogbomoso South, Surulere, Oriire, and Ogo-Oluwa. The estimated population of Ogbomoso is 654,183 , and estimated number of women in the reproductive age group is $163,546 .^{12}$

\section{Study design and study population}

This was a descriptive cross-sectional study conducted among women of reproductive age group, that is, 15-49 years of age.

\section{Sample size calculation}

To determine the sample size for the study, the formula used for population greater than 10,000 was used:

$$
n=\frac{z^{2} p q}{d^{2}}
$$

where $n=$ the minimum sample size when the population is more than 10,000 . 
$z=$ the standard normal deviate was set at 1.96 , which cor-

responds to $95 \%$ confidence level

$p=$ contraceptive prevalence rate (CPR) in South-West

Nigeria which was $0.317^{20}$

$q=1-p$

$d=$ degree of accuracy desired, which was set at 0.05

$n=\frac{(1.96)^{2} 0.317 \times 0.683}{0.05^{2}}$

$n=333$; however, 555 respondents were recruited for the study in order to eliminate bias due to nonresponsive individuals and ensure proper representation of the women.

\section{Sampling technique}

A multistage sampling technique was used in selecting the respondents. First step involved random selection by balloting of two wards from each of the five LGAs to give a total of ten wards.

Second step involved the random selection of four streets in each of the selected ward to make 40 streets. In the third step, 14 houses were systematically selected from each of the selected streets. The sampling interval was obtained by dividing the number of houses in the selected street by 14 . In the fourth step, eligible respondents in the selected households were interviewed. In households where there were more than one eligible respondent, one person was chosen by balloting.

\section{Instrument and data gathering}

The data were gathered by trained resident doctors in the Department of Obstetrics and Gynaecology as well as the Department of Community Medicine with the aid of semistructured questionnaires via interviewer-administered method. These doctors were trained by two of the principal researchers; they were taken through all the questions in the questionnaire to ensure uniformity and avoid ambiguity. Since the study was a community-based cross-sectional study, the questionnaires were administered in the evenings between 4 and $6 \mathrm{pm}$ when respondents were expected to be back at home from work. The questionnaire had sections on the sociodemographic data of the respondents, knowledge, and attitude toward the use of contraceptives, as well as the practice of contraception.

\section{Data analysis}

The questionnaires were manually checked for errors before entry into the computer and the data were analyzed using Statistical Package for Social Sciences (SPSS) version 17.
Respondents' attitude to contraception was first analyzed and presented based on individual responses to simple family planning-related positive attitude questions; composite attitude scores were thereafter computed for these questions by scoring 1 for strongly disagree, 2 for disagree, 3 for indifferent, 4 for agree, and 5 for strongly agree. Total scores of the respondents were summed up and the mean was computed. Any score at or above the average was taken as positive attitude and any score below the average was categorized as negative attitude. Frequency tables were generated and chi-square test was used to test for association between the variables. The $P$-value was set at $<0.05$ for the test statistics.

\section{Ethical issues}

Ethical approval for the study was obtained from the ethical committee of the Lautech Teaching Hospital Ogbomoso to conduct the research, and permission was sought from the appropriate authorities of the various LGAs, wards, and communities that were involved in the study. Verbal as well as written consent was obtained from individual respondents before recruiting them for the study. Confidentiality was ensured throughout the study period and respondents' questionnaires were identified with code numbers only, and not names.

\section{Results}

In this study, 555 respondents were recruited; however, only 546 respondents gave full responses to the questionnaire, giving a response rate of $97.5 \%$. The mean age of the respondent was $27.6 \pm 6.3$ years, with $58.4 \%$ (319) being in the age range of 20-29 years and $32.2 \%$ (176) being in the age range of 30-39 years. A majority $(61.0 \%$ [333]) of the respondents were married, $37.4 \%$ (204) were single, $1.0 \%$ (six) were separated from their husbands, $0.2 \%$ (one) was divorced, and $0.4 \%$ (two) were widows.

Respondents with tertiary education as their highest level of education were 367 (67.2\%); students constituted 35.0\% (191), professionals $23.1 \%$ (126), skilled workers $18.5 \%$, (101), unskilled $12.8 \%$ (70), and the unemployed $10.6 \%$ (58). Five hundred and fourteen (94.1\%) were Yoruba and 23 (77.5\%) of the respondents practiced Christianity (Table 1).

Table 2 shows respondents' knowledge about contraception. All the respondents were aware of contraception, and the commonest source of information was from health care personnel in the hospitals (255 [46.8\%]), other sources were family and friends (168 [30.7\%]), radio (60 [11.1\%]), television (36 [6.6\%]), print media (15 [2.8\%]) and electronic media (12 [2.1\%]). When asked about the 
Table I Sociodemographic characteristics of respondents $(n=546)$

\begin{tabular}{|c|c|c|}
\hline Variables & Frequency (n) & Percentage (\%) \\
\hline \multicolumn{3}{|l|}{ Age, years } \\
\hline $15-19$ & 25 & 4.6 \\
\hline $20-29$ & 319 & 58.4 \\
\hline $30-39$ & 176 & 32.2 \\
\hline $40-49$ & 26 & 4.8 \\
\hline \multicolumn{3}{|l|}{ Marital status } \\
\hline Single & 204 & 37.4 \\
\hline Married & 333 & 61.0 \\
\hline Separated & 6 & 1.0 \\
\hline Divorced & 1 & 0.2 \\
\hline Widowed & 2 & 0.4 \\
\hline \multicolumn{3}{|l|}{ Religion } \\
\hline Christian & 423 & 77.5 \\
\hline Muslim & 122 & 22.3 \\
\hline Traditional* & 1 & 0.2 \\
\hline \multicolumn{3}{|l|}{ Tribe } \\
\hline Yoruba & 514 & 94.1 \\
\hline Hausa & 14 & 2.6 \\
\hline lbo & 18 & 3.3 \\
\hline \multicolumn{3}{|c|}{ Highest educational level } \\
\hline None & 22 & 4.1 \\
\hline Primary & 39 & 7.1 \\
\hline Secondary & 118 & 21.6 \\
\hline Tertiary & 367 & 67.2 \\
\hline \multicolumn{3}{|l|}{ Occupation } \\
\hline Unemployed & 58 & 10.6 \\
\hline Student & 191 & 35.0 \\
\hline Professional & 126 & 23.1 \\
\hline Skilled worker & 101 & 18.5 \\
\hline Unskilled worker & 70 & 12.8 \\
\hline
\end{tabular}

Note: *Refers to those that worship the local deities.

uses of contraception, $416(76.1 \%)$ said it is meant to prevent unwanted pregnancies, 270 (49.5\%) said it is for child spacing, while 156 (28.6\%) said it is used to prevent STIs. Methods of contraception known to respondents included the traditional (local/unorthodox) (79 [4.4\%]), natural (194 [35.6\%]), and modern types (male condom [74.8\%], female condom [43.3\%], diaphragm [18.4\%], injectables [45.5\%], intrauterine contraceptive device [IUCD, 42.1\%], oral pills [57.7\%], implants [19.1\%], vasectomy [19.5\%], and bilateral tubal ligation [23.2\%]).

Four hundred and fifty four (83.1\%) respondents felt contraception has side effects/disadvantages, with irregular menses (221 [48.7\%]) and weight gain (201 [44.3\%]) being the leading side effects mentioned.

Table 3 shows respondents' responses to some questions, which reflect their attitude toward modern contraception. It was found that $~ 30 \%$ of them $(36.3 \%, 31.5 \%$ of respondents in each group) strongly agreed that using modern contraception is good and useful, respectively; $20 \%(22.7 \%, 21.8 \%$, $22.4 \%$ ) strongly agreed that it is beneficial, safe, and a healthy practice, respectively; and less than $20 \%$ of respondents
Table 2 Respondents' knowledge about contraception

\begin{tabular}{|c|c|c|}
\hline Variable & Frequency $(n)$ & Percentage (\%) \\
\hline \multicolumn{3}{|l|}{ Aware of contraceptives $(n=546)$} \\
\hline Yes & 546 & 100 \\
\hline No & 0 & 0 \\
\hline \multicolumn{3}{|l|}{ First source of information $(n=546)$} \\
\hline Radio & 60 & 11.0 \\
\hline Printed media & 15 & 2.8 \\
\hline Television & 36 & 6.6 \\
\hline Electronic media & 12 & 2.1 \\
\hline Hospital/health care personnel & 255 & 46.8 \\
\hline Family/friends & 168 & 30.7 \\
\hline \multicolumn{3}{|c|}{ Uses of contraception ( $n=536$ with multiple responses) } \\
\hline Prevents unwanted pregnancy & 416 & 76.1 \\
\hline Allows child spacing & 270 & 49.5 \\
\hline Prevents STI & 156 & 28.6 \\
\hline \multicolumn{3}{|c|}{ Methods known ( $\mathrm{n}=546$ with multiple responses) } \\
\hline Traditional (armlet, ring, padlock) & 79 & 14.4 \\
\hline $\begin{array}{l}\text { Natural (periodic abstinence, } \\
\text { coitus interruptus, lactational } \\
\text { amenorrhea) }\end{array}$ & 194 & 35.6 \\
\hline Male condom & 408 & 74.8 \\
\hline Female condom & 236 & 43.3 \\
\hline Diaphragm & 100 & 18.4 \\
\hline Injectables & 248 & 45.5 \\
\hline IUCD & 230 & 42.1 \\
\hline Pills & 315 & 57.7 \\
\hline Implants & 104 & 19.1 \\
\hline Vasectomy & 106 & 19.5 \\
\hline Bilateral tubal ligation & 127 & 23.2 \\
\hline \multicolumn{3}{|c|}{ Contraception has side effects/disadvantage $(n=546)$} \\
\hline Yes & 454 & 83.1 \\
\hline No & 92 & 16.9 \\
\hline \multicolumn{3}{|c|}{ Side effects known ( $\mathrm{n}=454$ with multiple responses) } \\
\hline Weight gain & 201 & 44.3 \\
\hline Weight loss & 89 & 19.5 \\
\hline Amenorrhea & 102 & 22.4 \\
\hline Heavy menses & 178 & 39.1 \\
\hline Secondary infertility & 130 & 28.7 \\
\hline Irregular menses & 221 & 48.7 \\
\hline Encourages promiscuity & 46 & 10.2 \\
\hline
\end{tabular}

Abbreviations: STI, sexually transmitted infection; IUCD, intrauterine contraceptive device.

$(15.5 \%, 19.5 \%, 19.1 \%, 18.2 \%$, and $18.7 \%)$ strongly agreed that modern contraception is reliable, positive, adequate, pleasant, and efficient, respectively. However 3.0\% strongly believed that contraception use is good, $2.1 \%$ strongly disagreed that it is useful, and $4.3 \%, 3.2 \%, 2.8 \%, 2.7 \%, 1.7 \%$, $3.6 \%, 3.6 \%$, and $3.6 \%$ strongly disagreed that it is healthy, reliable, beneficial, positive, safe, adequate, pleasant, and efficient, respectively. Many respondents agreed to these comments, some did not know, and some disagreed.

In Table 4, respondents who had ever used contraception before in their life time were $49.7 \%$ (271), while those among them using at the time of the study were $25.4 \%$ (69). 
Table 3 Respondents' attitude to modern contraception

\begin{tabular}{llllll}
\hline $\begin{array}{l}\text { Attitudinal comments } \\
\text { (using contraception is) }\end{array}$ & $\begin{array}{l}\text { Strongly agree, } \\
\mathbf{n}(\%)\end{array}$ & $\begin{array}{l}\text { Agree, } \\
\mathbf{n}(\%)\end{array}$ & $\begin{array}{l}\text { I do not know, } \\
\mathbf{n}(\%)\end{array}$ & $\begin{array}{l}\text { Disagree, } \\
\mathbf{n}(\%)\end{array}$ & $\begin{array}{l}\text { Strongly disagree, } \\
\mathbf{n}(\%)\end{array}$ \\
\hline Good & $198(36.3)$ & $211(38.7)$ & $63(I 1.5)$ & $57(10.5)$ & $17(3.0)$ \\
Useful & $172(31.5)$ & $259(47.5)$ & $62(I 1.3)$ & $4 I(7.5)$ & $12(2.1)$ \\
Healthy & $122(22.4)$ & $233(42.6)$ & $100(18.3)$ & $68(I 2.4)$ & $23(4.3)$ \\
Reliable & $84(15.5)$ & $228(41.7)$ & $98(17.9)$ & $118(21.7)$ & $18(3.2)$ \\
Beneficial & $124(22.7)$ & $255(46.7)$ & $9(18.1)$ & $5(9.6)$ & $15(2.8)$ \\
Positive & $106(19.5)$ & $234(42.8)$ & $124(22.7)$ & $67(I 2.3)$ & $15(2.7)$ \\
Safe & $119(21.8)$ & $244(44.8)$ & $101(18.5)$ & $72(13.2)$ & $9(1.7)$ \\
Adequate & $104(19.1)$ & $212(38.8)$ & $129(23.7)$ & $81(14.8)$ & $19(3.6)$ \\
Pleasant & $99(18.2)$ & $205(37.5)$ & $134(24.6)$ & $88(16.1)$ & $19(3.6)$ \\
Efficient & $102(18.7)$ & $216(39.5)$ & $127(23.3)$ & $81(14.9)$ & $19(3.6)$ \\
\hline
\end{tabular}

The methods being used were unorthodox type (4 [5.9\%]), natural type (2 [3.0\%]), and modern type (63 [91.1\%]). Explanations given by respondents who had used contraception before in their lifetime but were not using at the time of this study vary from no reason $(43.3 \%)$, to fear of side effects $(23.0 \%)$, to desire for more children $(17.2 \%)$, and even husbands' disapproval of use (16.5\%).

Composite attitude score of respondents toward modern contraception showed that $318(58.2 \%)$ had positive attitude, while 228 (41.8\%) had negative attitude (Table 4).

Table 5 shows the association between respondents who had ever used contraception and some demographic

Table 4 Contraception use among respondents and their categorized attitude to contraception

\begin{tabular}{lcc}
\hline Variable & Frequency $(\mathrm{n})$ & Percentage (\%) \\
\hline Ever used contraception $(\mathrm{n}=546)$ & & \\
Yes & $27 \mathrm{I}$ & 49.7 \\
No & 275 & 50.3 \\
Currently using contraception $(\mathrm{n}=27 \mathrm{I})$ & \\
Yes & 69 & 25.4 \\
No & 202 & 74.6 \\
Main reason for nonusage currently $(\mathrm{n}=202)$ & \\
No reason & 87 & 43.3 \\
Fear of side effects & 47 & 23.0 \\
Partner/husband's disapproval & 33 & 16.5 \\
Desire for more children & 35 & 17.2 \\
Class of contraception currently being used (n=69) & \\
Traditional & 4 & 5.9 \\
Natural & 2 & 3.0 \\
Modern & 63 & 91.1 \\
Duration of usage of present contraception (years) & $(\mathrm{n}=69)$ \\
$<\mathrm{I}$ & 2 & 2.1 \\
I-5 & 55 & 80.6 \\
$6-10$ & $1 \mathrm{I}$ & 16.0 \\
$>$ I0 & $\mathrm{I}$ & 1.4 \\
Categorized attitude to contraception (n=546) & \\
Positive & 318 & 58.2 \\
Negative & 228 & 41.8 \\
\hline
\end{tabular}

characteristics, such as respondents' awareness about side effects of contraception as well as respondents' attitude toward contraception. It was found that the older age group, the more educated, the married respondents, and those with positive attitude have used contraception more than the lesser age group, less educated, singles, and those with poor attitude, and the difference was found to be significant $(P<0.05)$. More of the respondents who were aware of the side effects associated with contraception use were found not to have used contraception compared with those who were not aware of side effects; however, this difference was not statistically significant $(P=0.593)$.

Table 5 Association among respondents' characteristics, attitude, and use of contraception

\begin{tabular}{|c|c|c|c|c|}
\hline \multirow[t]{3}{*}{ Variable } & \multicolumn{2}{|c|}{ Ever used contraception } & \multirow[t]{3}{*}{$\chi^{2}$} & \multirow[t]{3}{*}{$P$-value } \\
\hline & Yes & No & & \\
\hline & Frequency (\%) & Frequency (\%) & & \\
\hline \multicolumn{5}{|l|}{ Age, years } \\
\hline $15-19$ & $7(27.3)$ & I8 (72.7) & 44.643 & $<0.000 I^{*}$ \\
\hline $20-29$ & $127(39.8)$ & $192(60.2)$ & & \\
\hline $30-39$ & II $3(64.2)$ & $63(35.8)$ & & \\
\hline $40-49$ & $22(84.6)$ & $4(I 5.4)$ & & \\
\hline \multicolumn{5}{|l|}{ Marital status } \\
\hline Single & $56(27.6)$ & I 48 (72.4) & 72.974 & $<0.000$ I* \\
\hline Married & $210(63.1)$ & $123(36.9)$ & & \\
\hline Separated & I (I6.7) & $5(83.3)$ & & \\
\hline Divorced & $0(0.0)$ & I $(100.0)$ & & \\
\hline Widowed & $2(100.0)$ & $0(0.0)$ & & \\
\hline \multicolumn{5}{|c|}{ Educational status } \\
\hline None & $6(27.8)$ & $16(72.2)$ & 9.995 & $0.019 *$ \\
\hline Primary & $20(51.4)$ & $19(48.6)$ & & \\
\hline Secondary & 74 (62.9) & 44 (37.I) & & \\
\hline Tertiary & $198(53.9)$ & $169(46.1)$ & & \\
\hline \multicolumn{5}{|c|}{ Awareness of side effects } \\
\hline Yes & $223(49.2)$ & $231(50.8)$ & 0.286 & 0.593 \\
\hline No & $48(52.7)$ & $44(47.3)$ & & \\
\hline \multicolumn{5}{|c|}{ Categorized attitude } \\
\hline Positive & I8I (57.0) & $137(43.0)$ & 16.165 & $<0.0001 *$ \\
\hline Negative & $90(39.3)$ & $138(60.7)$ & & \\
\hline
\end{tabular}

Note: *Statistically significant. 
The predictors of using contraception are given in Table 6. The odds ratio of those in age group 40-49 years using contraception more than the age group of 15-19 years was 14.1 (OR 14.1; CI 3.06-73.24; $P=0.0001$ ), the married were approximately four times more likely to use contraception than the singles (OR 4.5; CI 3.03-6.72; $P<0.0001$ ), those with tertiary level of education were three times more likely to use contraception than those without formal education (OR 3.1; CI 1.13-9.95; $P=0.0268$ ), and the odds ratio of respondents with positive attitude toward using contraception more than those with negative attitude was 2 (OR 2; CI 1.41-2.91; $P<0.0001)$.

\section{Discussion}

This study carried out among the women of reproductive age group in Ogbomoso metropolis showed that the highest age group of respondents was in the range 20-29 years. This trend was also found in a similar community-based study where about half of respondents surveyed were in this age range. ${ }^{21}$ The mean age obtained in this study was also close to that obtained from a study conducted at Ibadan, ${ }^{22}$ another city in Oyo State, Nigeria.

Approximately, six out of every ten respondents in our study were married. According to previous studies, contraception prevalence rate among women was in the range of six to seven for every ten respondents that were married..$^{21-24}$ However, other studies carried out among rural women in Ikeji Arakeji, south-western part of Nigeria, ${ }^{25}$ and among women attending antenatal clinic in Uyo, southern part of Nigeria, ${ }^{26}$ showed a higher percentage of respondents to be married (97.1\% and 93.7\%, respectively). These higher percentages, compared to our study, may be due to the fact that the Ikeji Arakeji study was carried out among rural women, and the majority of women in the reproductive age group being married is an indicator of a rural environment; ${ }^{25}$ the Uyo study was carried out among antenatal attendees who were pregnant and were also expected to be married.

All the respondents in this study were aware of contraception, a finding similar to previous studies that have shown high level of awareness of contraception among women. ${ }^{13,23,25-28}$ Various studies have shown mass media to be the most common source of information about contraception in Nigeria. ${ }^{21,28,29}$ This is contrary to our study where the first most common source of information about contraception was from health care workers. Our study probed for the first source of information, and not for the most common source generally; mass media due to repeated jingles and campaigns is naturally expected to be the most common source generally, but this may differ as is the case with our study where the first source of information may not be the most common source of information. However, some other studies have also shown either the doctors or nurses or other health care workers to be the most common source of information about contraception for women. ${ }^{26,30}$ Over $70 \%$ of the respondents in this study were aware of the male condom, but the studies have shown that the use of condoms

Table 6 Predictors of ever using contraception

\begin{tabular}{|c|c|c|c|c|c|}
\hline \multirow[t]{3}{*}{$\overline{\text { Variable }}$} & \multicolumn{2}{|c|}{ Ever used contraception } & \multirow[t]{3}{*}{ OR } & \multirow[t]{3}{*}{$95 \% \mathrm{Cl}$} & \multirow[t]{3}{*}{$P$-value } \\
\hline & Yes & No & & & \\
\hline & Frequency (\%) & Frequency (\%) & & & \\
\hline \multicolumn{6}{|l|}{ Age, years } \\
\hline $15-19$ (ref) & $7(27.3)$ & $18(72.7)$ & 1 & & \\
\hline $20-29$ & $127(39.8)$ & $192(60.2)$ & 1.7 & $0.65-4.63$ & 0.3404 \\
\hline $30-39$ & $113(64.2)$ & $63(35.8)$ & 4.6 & $1.70-12.95$ & 0.0012 \\
\hline $40-49$ & $22(84.6)$ & $4(15.4)$ & 14.1 & $3.06-73.24$ & 0.0001 \\
\hline \multicolumn{6}{|l|}{ Marital status } \\
\hline Single (ref) & $56(27.6)$ & | 48 (72.4) & I & & \\
\hline Married & $210(63.1)$ & $123(36.9)$ & 4.5 & $3.03-6.72$ & $<0.0001$ \\
\hline Separated & I (I6.7) & $5(83.3)$ & 0.5 & $0.01-4.89$ & 1.0000 \\
\hline Divorced & $0(0.0)$ & $\mathrm{I}(100.0)$ & 0.0 & $0.00-103.77$ & 1.0000 \\
\hline \multicolumn{6}{|c|}{ Educational status } \\
\hline None (ref) & $6(27.8)$ & $16(72.2)$ & 1 & & \\
\hline Primary & $20(5 \mathrm{I} .4)$ & $19(48.6)$ & 2.8 & $0.80-10.18$ & 0.1208 \\
\hline Secondary & $74(62.9)$ & $44(37.1)$ & 4.5 & $1.50-14.9 \mid$ & 0.0044 \\
\hline Tertiary & $198(53.9)$ & $169(46.1)$ & 3.1 & $1.13-9.95$ & 0.0268 \\
\hline \multicolumn{6}{|c|}{ Categorized attitude } \\
\hline Negative & $90(39.3)$ & $138(60.7)$ & 1 & $|.4|-2.9 \mid$ & $<0.0001$ \\
\hline Positive & $18 \mid(57.0)$ & I 37 (43.0) & 2.0 & & \\
\hline
\end{tabular}

Abbreviations: $\mathrm{OR}$, odds ratio; $\mathrm{Cl}$, confidence interval; ref, reference. 
has not been commensurable with its awareness. Although there has been a slight increase in the use of condoms for dual protection in the past 2 decades, ${ }^{31,32}$ some researchers suggest that women relying on user-independent methods such as IUCD or hormonal methods may not likely seek the added protection of condoms. ${ }^{32-34}$ While user-independent methods reduce the risk of unplanned pregnancy, they offer no protection against STIs, including HIV/AIDS. The use of condoms along with other methods has therefore been advised to be considered seriously as defense against both unplanned pregnancy and STIs. ${ }^{32}$

In spite of all the awareness about contraception among all the respondents in this study, only about half of them had ever used contraception while only about a quarter were currently using contraception. Contraceptive use has been persistently low in Nigeria,,$^{21,22,25,30,35}$ and the demographic health surveys have also shown little or no improvement in the contraceptive prevalence rate among women in Nigeria over time. ${ }^{12,13,36}$ In the demographic health surveys as well as previous studies, high level of awareness and knowledge about contraception have been found among respondents but with an opposing low contraceptive use, ${ }^{12,13,21,25,26,28,36}$ and this supports the findings in our study. The implication of low contraceptive use varies from unwanted pregnancies, with its attending illegal unsafe abortions, ${ }^{21,27}$ to population explosion. ${ }^{24}$ With a current population of over 150 million and a growth rate of $\sim 2.4 \%$ per annum, Nigeria is the most populous country in Africa. ${ }^{37}$ Population explosion leads to a reduction in the "carrying capacity" of the ecosystem, bringing overexploitation, depletion, and pressure on natural resources, and thus threatening public health. ${ }^{38}$

Another interesting finding in this study was that two-fifths of respondents who were not currently using contraception during the study did not have any reason for nonusage; this was also observed in a similar study ${ }^{30}$ carried out in Calabar, southern part of Nigeria. Respondents having no reason for not using contraception in spite of being at risk of unwanted pregnancies reflects their attitude to contraception. Our study further corroborates this finding with two-fifths of the respondents found to have poor attitude to contraception when attitude scores were categorized. Another common reason given for nonusage of contraception was fear of side effects; this was also a common finding in previous studies. ${ }^{21,22,24,30}$ Although some contraceptive methods are in fact associated with side effects, a series of focus group discussions carried out among young women in Benin, Southern Nigeria, revealed that many of the concerns that prevented them from using contraceptives were based on misinformation about the nature of these side effects. ${ }^{27}$ Other reasons for nonutilization of contraception were the desire to have more children, which has been observed in previous studies too, ${ }^{22,24,30}$ and husband/partner's disapproval, which has also been seen in previous studies. ${ }^{24,26,30}$ In the past, family planning programs have focused on women's attitudes and behaviors. Women were considered the main targets for information, education, and communication on contraceptive knowledge and use. However, social and cultural factors have been shown to influence the decision to use or not to use contraception, even when the contraceptives are available. ${ }^{39,40} \mathrm{Men}$, who are highly influential in the family's decision-making, should not be ignored. The role of male partners in the success of female reproductive health in Nigeria and Africa as a whole cannot be overemphasized. Exclusion of men from active involvement in reproductive health issues represents a lack of appreciation of the social reality of daily living in most developing societies, particularly in Africa. ${ }^{41}$ The use of contraception has been associated with husband/partner's support. ${ }^{25}$

Awareness of side effects did not significantly affect the use of contraception, but older age, higher educational status, being married, and having positive attitude to contraception were all factors that positively and significantly influenced the use of contraception in our study. Previous studies have also shown that a greater number of married women use contraception than the single, divorced, or widowed individuals, ${ }^{23}$ and women with either secondary or tertiary level of education have been found to utilize contraception more than those with either primary education or no formal education. ${ }^{13,23-26}$

\section{Conclusion}

This research showed that all the women who were surveyed were in their reproductive ages and that they were aware of contraception, but only half had ever used contraception, and fewer people were currently using it, resulting in a very low prevalence rate of contraceptive use. This signifies that high level of awareness did not translate to high contraceptive use. In light of the advantages associated with contraception use, there needs to be a conscious effort, especially among health care workers, to educate women about contraception and encourage its use. Reproductive health programs and policies should adequately involve male partners/men, as this has been found to help in promoting maternal health. ${ }^{42,43}$ Researchers should seek to explore all avenues to make contraception a "couple thing" from inception, providing joint enlightenment, and educating the couple regarding the advantages may help to increase the uptake of contraceptives. 


\section{Disclosure}

The authors report no conflicts of interest in this work.

\section{References}

1. Oyedokun AO. Determinants of contraceptive usage: lessons from women in Osun State, Nigeria. J Humanit Soc Sci. 2007;1(2):1-14.

2. USAID/HPI. Achieving Equity for the Poor in Kenya: Understanding Level of Inequities and Barriers to Family Planning Services. Futures Group International, Nairobi: 2007.

3. Health Policy Initiatives (HPI). Inequalities in the Use of Family Planning and Reproductive Health Services: Implications for Policies and Programs. USAID/HPI Task Order 1, Washington DC: 2007.

4. Okech TC, Wawire NW, Mburu TK. Contraceptive use among women of reproductive age in Kenya's city slums. Int J Bus Soc Sci. 2011;2: 22-43.

5. Akani C, Enyindah C, Babatunde S. Emergency contraception: knowledge and perception of female undergraduates in the Niger Delta of Nigeria. Ghana Med J. 2008;42:68-70.

6. Physicians for Reproductive Health and Choice (PRHC). An Overview of Abortion in the United States. Stop Forced Abortions Alliance, USA: 2003.

7. World Health Organization. Unsafe Abortion: Global and Regional Estimates of the Incidence of Unsafe Abortion and Associated Mortality in 2004. WHO, Geneva: 2004.

8. Abe E, Omo-Aghoja L. Maternal mortality at the Central Hospital, Benin City Nigeria: a ten year review. Afr J Reprod Health. 2008;12:17-26.

9. Adewale I. Trends in postabortal mortality and morbidity in Ibadan, Nigeria. Int J Gynecol Obstet. 1992;38:115-118.

10. Omo-Aghoja L, Omo-Aghoja V, Aghoja C. Factors associated with the knowledge, practice and perceptions of contraception in rural southern Nigeria. Ghana Med J 2009;43:115-121.

11. Adebimpe WO, Asekun-Olarinmoye EO. A comparative study of contraceptive use among rural and urban women in Osun State, Nigeria. Int J Trop Dis Heal. 2012;2:214-224.

12. National Population Commission (NPC). Nigeria Demographic and Health Survey 2003. NPC, Abuja: 2004

13. National Population Commission (NPC) [Nigeria] and ICF International. Nigeria Demographic and Health Survey 2013. NPC, Abuja: 2014.

14. National Population Commission Federal Republic of Nigeria. Revised Population Policy in Nigeria. 2004.

15. Adebowale SA, Adeoye IA, Palamuleni ME. Contraceptive use among Nigerian women with no fertility intention: interaction amid potential causative factors. African Popul Stud. 2013;27:127-139.

16. Moreland S, Talbird S. 'Achieving the Millennium Development Goals: The Contribution of Fulfilling the Unmet Need for Family Planning.' USAID, New York: 2006.

17. Hawkins J, Matteson PS, Tabeek ES. A Comprehensive Handbook. Woods NF, editor. Sage Publishers; London: 1995.

18. Odimegwu CO, Ojo M, Siyagande A. Regional correlates of choice of contraceptive methods in Nigeria. Korea J Popul Dev. 1997;26: 131-145.

19. Odimegwu CO. Family planning attitudes and use in Nigeria: a factor analysis. Int Fam Plan Perspect. 1999;25:86-91.

20. National Population Commission Federal Republic of Nigeria Abuja Nigeria. Nigeria Demographic and Health Survey. NPC, Abuja: 2008.

21. Sedgh G, Bankole A, Oye-Adeniran B, Adewole IF, Singh S, Hussain R. Unwanted pregnancy and associated factors among Nigerian women. Int Fam Plan Perspect. 2006;32:175-184.

22. Omokhodion F, Onadeko M, Balogun O. Contraceptive use among hairdressers in South-west Nigeria. J Obstet Gynecol. 2007;27:612-614.

23. Envuladu EA, Agbo HA, Mohammed A, Chia L, Kigbu JH, Zoakah AI. Utilization of modern contraceptives among female traders in Jos South LGA of Plateau state, Nigeria. Int J Med Biomed Res. 2012;1: 224-231.
24. Asekun-Olarinmoye EO, Adebimpe WO, Bamidele JO, Odu OO, Asekun-Olarinmoye IO, Ojofeitimi EO. Barriers to use of modern contraceptives among women in an inner city area of Osogbo metropolis, Osun State, Nigeria. Int J Womens Health. 2013;5:647-655.

25. Odusina E, Ugal D, Olaposi O. Socio-economic status, contraceptive knowledge and use among rural women in Ikeji Arakeji, Osun State, Nigeria. Afro Asian J Soc Sci. 2012;3:1-10.

26. Umoh AV, Abah MG. Contraception awareness and practice among antenatal attendees in Uyo, Nigeria. Pan Afr Med J. 2011;10:53.

27. Otoide VO, Oronsaye F, Okonofua FE. Why Nigerian adolescents seek abortion rather than contraception: evidence from focus-group discussions. IntFam Plan Perspect. 2001;27:77-81.

28. Adeyinka AR, Oladipupo A, Omisore AO. Knowledge and practice of contraception among women of reproductive ages in South West Nigeria. Int J Eng. 2015;1:70-76.

29. Duru C, Ifeadike CO, Nnebue CC, Ubajaka C, Onyeonoro U, Ajaegbu O. Contraceptive knowledge and practice among female teachers of reproductive age, in Nnewi, Anambra State. Afrimedic J. 2011;2:21-27.

30. Eko JE, Osonwa KO, Osuchukwu NC, Offiong DA. Prevalence of contraceptive use among women of reproductive age in Calabar Metropolis, Southern Nigeria. Int J Humanit Soc Sci Invent. 2013;2:27-34.

31. Santelli J, Morrow B, Anderson J, Lindberg L. Contraceptive use and pregnancy risk among US high school students, 1991-2003. Perspect Sex Reprod Heal. 2006;38:106-111.

32. Pazol, K. Condoms for dual protection: patterns of use with highly effective contraceptive methods. Public Health Rep. 2010;125:208-217.

33. Darney P, Callegari L, Swift A, Atkinson E, Robert, A. Condom practices of urban teens using Norplant contraceptive implants, oral contraceptives and condoms for contraception. Am J Obs Gynecol. 1999;180:929-937.

34. Sayegh M, Fortenberry J, Shew M, Orr D. The developmental association of relationship quality, hormonal contraceptive choice and condom non-use among adolescent women. $J$ Adolesc Heal. 2006;39: 388-395.

35. Igbodekwe FC, Oadimeji O, Oladimeji KE, Adeoye IA, Akpa OM, Lawson L. Utilisation of modern contraceptive among women of childbearing age in resource constraint setting: evidence from 2008 National Demographic and Health Survey in Nigeria. J Heal Sci. 2014;4:72-78.

36. NPC [Nigeria] and ICF Macro. Nigeria Demographic and Health Survey 2008. NPC, Abuja: 2009.

37. Population Reference Bureau. Nigeria. 2007. Available from: http:// www.prb.org/Countries/Nigeria.aspx.

38. Hinrichsen D, Robey B. Population and the environment: the global challenge. Popul Rep. 2000;15:212-218.

39. Caldwell J, Caldwell P. Population Growth and Reproduction in SubSaharan Africa. Technical Analysis of Fertility and Its Consequences. World Bank, Washington DC; 1990:199-214.

40. Tuloro T, Deressa W, Ali A, Davey G. The role of men in contraceptive use and fertility preference in Hossana Town, southern Ethiopia. Ethiop J Heal Dev. 2006;20:152-159.

41. Olugbenga-belloAI, Asekun-olarinmoye EO, Adewole AO, Adeomi AA, Olarewaju SO. Perception, attitude and involvement of men in maternal health care in a Nigerian community. J. Public Heal Epidemiol. 2013;5:262-270.

42. Cohen S, Burger M. Partnering: A New Approach to Sexual and Reproductive Health; Technical Paper No 3. UNFPA, New York: 2000.

43. Mullay B, Hindin M, Becker S. Can women's autonomy impede male involvement in pregnancy health in Kathmandu, Nepal? Soc Sci Med. 2005;61:93-102. 
Open Access Journal of Contraception

Dovepress

\section{Publish your work in this journal}

Open Access Journal of Contraception is an international, peerreviewed, open access, online journal, publishing original research, reports, reviews and commentaries on all areas of contraception. In addition to clinical research, demographics and health-related aspects, the journal welcomes new findings in animal and preclinical studies

relating to understanding the biological mechanisms and practical development of new contraceptive agents. The manuscript management system is completely online and includes a very quick and fair peer-review system. Visit http://www.dovepress.com/testimonials.php to read real quotes from published authors.

Submit your manuscript here: http://www.dovepress.com/open-access-journal-of-contraception-journal 